\title{
Hybrid Sulfur Recovery Process for Natural Gas Upgrading Quarterly Technical Report
}

Reporting Period Start Date: 1/1/04

Reporting Period End Date: 3/31/04

Principal Author:

Dennis Dalrymple, CrystaTech, Inc.

April 2004

DOE No. DE-FC26-99FT40725

CrystaTech, Inc.

4616 West Howard Lane, Suite 2500

Austin, Texas 78728 


\section{DISCLAIMER}

This report was prepared as an account of work sponsored by an agency of the United States Government. Neither the United States Government nor any agency thereof, nor any of their employees, makes any warranty, express or implied, or assumes any legal liability or responsibility for the accuracy, completeness, or usefulness of any information, apparatus, product, or process disclosed, or represents that its use would not infringe privately owned rights. Reference herein to any specific commercial product, process, or service by trade name, trademark, manufacturer, or otherwise does not necessarily constitute or imply its endorsement, recommendation, or favoring by the United States Government or any agency thereof. The views and opinions of authors expressed herein do not necessarily state or reflect those of the United States Government or any agency thereof. 


\begin{abstract}
This first quarter report of 2004 describes progress on a project funded by the U.S. Department of Energy (DOE) to test a hybrid sulfur recovery process for natural gas upgrading. The process concept represents a low-cost option for direct treatment of natural gas streams to remove $\mathrm{H}_{2} \mathrm{~S}$ in quantities equivalent to $0.2-25$ metric tons (LT) of sulfur per day. This process is projected to have lower capital and operating costs than the competing technologies, amine/aqueous iron liquid redox and amine/Claus/tail gas treating, and have a smaller plant footprint, making it well suited to both on-shore and off-shore applications.

CrystaSulf ${ }^{\circledR}$ (service mark of CrystaTech, Inc.) is a new nonaqueous sulfur recovery process that removes hydrogen sulfide $\left(\mathrm{H}_{2} \mathrm{~S}\right)$ from gas streams and converts it into elemental sulfur. CrystaSulf features high sulfur recovery similar to aqueous-iron liquid redox sulfur recovery processes, but differs from the aqueous processes in that CrystaSulf controls the location where elemental sulfur particles are formed. In the hybrid process, approximately $1 / 3$ of the total $\mathrm{H}_{2} \mathrm{~S}$ in the natural gas is first oxidized to $\mathrm{SO}_{2}$ at low temperatures over a heterogeneous catalyst. Low temperature oxidation is done so that the $\mathrm{H}_{2} \mathrm{~S}$ can be oxidized in the presence of methane while avoiding methane oxidation and fouling due to coking from other hydrocarbon contaminants.
\end{abstract}

The project involves the development of a catalyst using laboratory/bench-scale catalyst testing, and then demonstration of the catalyst at CrystaTech's pilot plant site in west Texas. 


\section{TABLE OF CONTENTS}

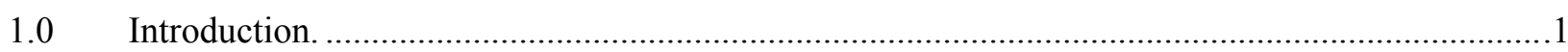

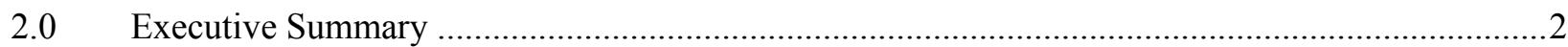

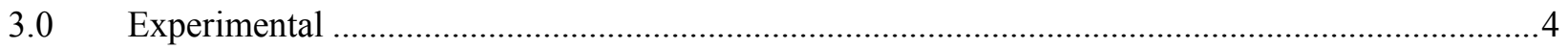

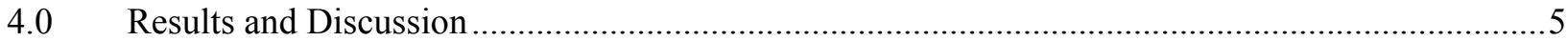

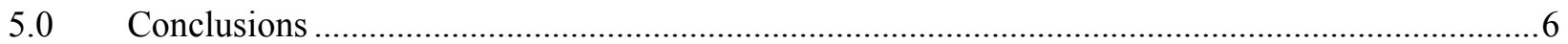




\subsection{INTRODUCTION}

This quarterly report is the thirteenth technical report for DOE Contract No. DE-FC2699FT40725 entitled "Hybrid Sulfur Recovery Process for Natural Gas Upgrading" following novation of the project from URS Corporation to CrystaTech, Inc. The CrystaSulf process is a new nonaqueous sulfur recovery process that removes hydrogen sulfide $\left(\mathrm{H}_{2} \mathrm{~S}\right)$ from gas streams and converts it into elemental sulfur. The hybrid CrystaSulf process uses a catalyst to first oxidize about $1 / 3$ of the $\mathrm{H}_{2} \mathrm{~S}$ to $\mathrm{SO}_{2}$. 


\subsection{EXECUTIVE SUMMARY}

This project was funded by the U.S. Department of Energy (DOE) to test a hybrid sulfur recovery process for natural gas upgrading. The process concept represents a low-cost option for direct treatment of natural gas streams to remove $\mathrm{H}_{2} \mathrm{~S}$ in quantities equivalent to $0.2-25$ metric tons (LT) of sulfur per day. This process is projected to have lower capital and operating costs than the competing technologies, amine/aqueous iron liquid redox and amine/Claus/tail gas treating, and have a smaller plant footprint, making it well suited to both on-shore and off-shore applications.

CrystaSulf is a new nonaqueous sulfur recovery process that removes hydrogen sulfide $\left(\mathrm{H}_{2} \mathrm{~S}\right)$ from gas streams and converts it into elemental sulfur. CrystaSulf features high sulfur recovery similar to aqueous-iron liquid redox sulfur recovery processes, but differs from the aqueous processes in that CrystaSulf controls the location where elemental sulfur particles are formed. In the hybrid process, approximately $1 / 3$ of the total $\mathrm{H}_{2} \mathrm{~S}$ in the natural gas is first oxidized to $\mathrm{SO}_{2}$ at low temperatures over a heterogeneous catalyst. Low temperature oxidation is done so that the $\mathrm{H}_{2} \mathrm{~S}$ can be oxidized in the presence of methane while avoiding methane oxidation and fouling due to coking from other hydrocarbon contaminants.

CrystaTech, Inc. owns the intellectual property (U.S. Patent No. 6,416,729) associated with using an upstream catalyst in conjunction with CrystaSulf to produce a hybrid process. In CrystaTech's patent, the catalyst can produce $\mathrm{SO}_{2}$ alone or $\mathrm{SO}_{2}$ plus sulfur. Previous results from this study showed that the hybrid CrystaSulf process based on $\mathrm{SO}_{2}$ producing catalyst is a viable process for treating natural gas. Calculations indicated that natural gas streams containing a fairly wide range of $\mathrm{H}_{2} \mathrm{~S}$ concentrations and pressures of interest -- i.e., pressures up to $6.89 \mathrm{MPa}(1000$ psi) -- could be processed by the hybrid CrystaSulf process. In addition, previous testing with TDA's modified catalysts showed that they exhibit high $\mathrm{H}_{2} \mathrm{~S}$ conversion $(99+\%)$ with essentially no slip of oxygen. Further, changing the formulation, temperature, and $\mathrm{O}_{2} / \mathrm{H}_{2} \mathrm{~S}$ ratio can be used to control $\mathrm{SO}_{2}$ selectivity over these catalysts. However, the value of a specific catalyst in this hybrid process is not just a function of its technical performance in laboratory/pilot studies; it is also a direct function of its cost (which may include license fees, transportation, and the cost of the catalyst itself) and commercial availability.

As discussed previously, we have been unable to reach a reasonable agreement with TDA regarding commercial use of their catalyst. TDA signed an agreement which gives MI exclusive license to TDA's direct oxidation catalyst. MI now markets a process, SulfaTreat-DO, which uses TDA's catalyst upstream of SulfaTreat scavenger. MI, TDA, and this technology are now competing in the marketplace with CrystaSulf-based sulfur technology. This development complicates and possibly eliminates our ability to use TDA's catalyst for future commercial plants. In addition, GTI budget constraints continue and will prevent them being able to provide the support we had hoped would allow us to test an alternate catalyst.

On the positive side, there is an opportunity to move the hybrid technology forward working with ChevronTexaco and DOE in the area of syngas treatment. That opportunity has firmed up considerably during the last quarter. We will use either Axens CRS 31 catalyst in that program or a proprietary DOE catalyst. We expect to have contracts in place in May. As a result of the events which complicated the ability to move the hybrid technology forward based on TDA catalyst technology and the new opportunity to move it forward with Axens or DOE catalyst technology, we have determined, in conjunction with the DOE project officer, to complete this project by writing a final report documenting the results and showing how these results have led to the opportunity for future development of the hybrid technology under the ChevronTexaco/DOE program described above. 


\subsection{EXPERIMENTAL}

No experimental work was performed during this quarter and no additional experimental work under this project is planned.

\subsection{Catalyst Sources}

As discussed in prior quarterly reports, we identified several alternate sources of catalyst when the ability to use TDA catalyst became in doubt. The most promising commercially available catalyst for the hybrid process is CRS 31, which is supplied by Axens North America. Axens is a major worldwide supplier of sulfur conversion catalyst. They report that CRS 31 (which is $\mathrm{TiO}_{2}$-based) can be used for COS hydrolysis and $\mathrm{H}_{2} \mathrm{~S}$-to-sulfur $/ \mathrm{SO}_{2}$ conversion depending on reactor conditions (mainly temperature and oxygen stoichiometry). This catalyst was the original "direct oxidation" catalyst (patents have expired), and Axens provides it to Claus plants worldwide. This catalyst has also been used in many well-known industrial processes which oxidize $\mathrm{H}_{2} \mathrm{~S}$ (e.g., Linde's Clinsulf process). Further, they have indicated that hydrocarbon fouling/cracking should not be a problem as long as reactor temperatures are below $250^{\circ} \mathrm{C}\left(482^{\circ}\right.$ F), approximately the maximum temperature we have contemplated). Recently Axens announced a companion catalyst, CSM 31, which can be used in conjunction with CRS 31 to further enhance its ability to resist hydrocarbon fouling. The CSM 31/CRS 31 combination provides high resistance to hydrocarbon fouling/cracking at temperatures well in excess of $250^{\circ} \mathrm{C}$. While we do not anticipate operating at these temperatures, the flexibility to do so if needed could be an asset in the future. As additional benefits to the Axens catalysts, they have extensive catalyst testing and development facilities, and their catalyst is available for less than $\$ 5 / \mathrm{lb}$. GTI and CrystaTech signed agreements with Axens to test their catalyst last quarter.

While the opportunities associated with using Axens as the source of catalyst for the hybrid process sound very promising, we have recently learned that DOE has catalyst technology that may also fit. In recent discussions with the NETL staff in Morgantown, we learned that DOE had earlier developed and tested metal oxide direct oxidation catalysts along the development path of DOE's SCOHS (Selective Catalytic Oxidation of Hydrogen Sulfide) process. The DOE metal oxide catalysts performed satisfactorily for bulk $\mathrm{H}_{2} \mathrm{~S}$ removal, but the target for SCOHS is ppb levels of $\mathrm{H}_{2} \mathrm{~S}$ in the product gas so they were abandoned in favor of carbon based materials. Use of DOE catalyst technology in the hybrid process is a very real possibility and one that we will evaluate in the upcoming ChevronTexaco/DOE program if it is approved.

\subsection{Laboratory Testing}

As noted above, no experimental work was performed during this quarter and no additional experimental work under this project is planned.

\subsection{Pilot Unit Testing}

Again, as noted above, no experimental work was performed during this quarter and no additional experimental work under this project is planned. As discussed last quarter, CrystaTech's pilot unit testing facility is located at Oxy Permian's DUCRP plant just outside

Denver City, Texas, and agreement with Oxy calls for us to dismantle and remove the CrystaSulf unit once we no longer have testing planned. We will remove the unit during the second quarter of 2004 . 


\subsection{RESULTS AND DISCUSSION}

The goal of this project has been to gather bench scale and then pilot scale test data regarding use of an " $\mathrm{SO}_{2}$ catalyst" upstream of CrystaSulf. This type of catalyst converts $1 / 3$ of the inlet $\mathrm{H}_{2} \mathrm{~S}$ to $\mathrm{SO}_{2}$, thus supplying the $\mathrm{SO}_{2}$ needed for the CrystaSulf process. CrystaSulf utilizes liquid Claus reactions and requires a feed gas with an $\mathrm{H}_{2} \mathrm{~S}$ to $\mathrm{SO}_{2}$ ratio of $2: 1$. Combining CrystaSulf with this upstream $\mathrm{SO}_{2}$ catalyst eliminates the costs of other $\mathrm{SO}_{2}$ introduction options - i.e., operating cost of importing liquid $\mathrm{SO}_{2}$ or the capital and operating cost of installing and operating a sulfur burner. The potential impacts of using an $\mathrm{SO}_{2}$ catalyst are lower operating costs and possibly lower capital costs, depending on the size of the system.

This project was novated and then extended to allow it to proceed amidst organizational changes. During the life of this project to advance the hybrid (CrystaSulf plus catalyst) process, we have generated a considerable body of small-scale test data including data taken on a raw gas stream at the Oxy commercial site. We have also advanced the commercial viability of the core CrystaSulf process. In addition, we have conducted considerable engineering and economic analyses regarding the performance and costs of the hybrid process. One key finding has been that using the catalyst section to convert the bulk of the $\mathrm{H}_{2} \mathrm{~S}$ in the inlet gas to elemental sulfur (which is removed prior to the CrystaSulf absorber) provides process economics that are substantially better that just using the catalyst to make $\mathrm{SO}_{2}$. As a result, the development path has shifted to focus on this sulfur plus $\mathrm{SO}_{2}$ configuration of the hybrid process (which CrystaTech has named "CrystaSulf-DO”).

We believe this project has advanced the hybrid technology considerably. However, due to the factors discussed earlier, taking the hybrid technology to commercial readiness along the originally targeted natural gas treatment path outlined for this project is no longer feasible. While that is a major disappointment, we are encouraged that an alternate path to commercialize the technology has been identified and that this project allowed us to keep the development process alive and positioned it for the new commercialization path. 


\subsection{CONCLUSIONS}

The results of this project have shown that oxidation catalyst can convert $\mathrm{H}_{2} \mathrm{~S}$ to $\mathrm{SO}_{2}$ under synthesized laboratory conditions and actual plant gas in the field. Under this project engineering and cost data were also developed. However, the path to commercialization via natural gas related R\&D is no longer feasible. Nonetheless, a path to commercialization does exist via coal gasification/syngas research and development. DOE's budgets and priorities in gas treatment have increasingly been shifting toward coal gasification and syngas treatment with Clean Coal, FutureGen and other high priority areas. As it turns out, the "hybrid" process concept can be extended by use of selected oxidation catalysts and conditions which not only eliminate the sulfur burner by making $\mathrm{SO}_{2}$ from inlet gas $\mathrm{H}_{2} \mathrm{~S}$, but also provide bulk sulfur removal upstream of CrystaSulf. This extension of the process concept has the potential to provide considerable cost reduction and performance benefits for coal-based plants. CrystaTech has gained support from ChevronTexaco for evaluating and developing the incorporation of this hybrid process variant into their gasification plant technology and a joint program with DOE in the gasification area now is being put into place. The primary remaining task on this project is to prepare the final report, which will be completed before the June 30, 2004 project end date. 